Rev. Inst. Flor. v. 28 n. 2 p. $159-175$ dez. 2016

http://dx.doi.org/10.24278/2178-5031.201628206

ISSN impresso 0103-2674/on-line 2178-5031

\title{
PLANTIOS FLORESTAIS COM PINUS NO ESTADO DO PARANÁ E OS NOVOS CENÁRIOS DEFINIDOS PELAS MUDANÇAS CLIMÁTICAS GLOBAIS ${ }^{1}$
}

\section{NEW SCENARIOS OF THE REGIONS WITH THE POTENTIAL FOR FOREST PLANTATIONS WITH PINUS IN PARANÁ STATE ON GLOBAL CLIMATE CHANGE}

\author{
Marcos Silveira WREGE ${ }^{2,5}$; Paulo Henrique CARAMORI'; \\ Marilice Cordeiro GARRASTAZU²; Elenice FRITZSONS²; \\ Adriane PARTALA ${ }^{4}$; Georgia Luize CHRISTENSEN ${ }^{4}$
}

\begin{abstract}
RESUMO - O Brasil ocupa posição de destaque mundial no setor florestal, com produtividade elevada e baixo custo de produção, concentrando os plantios florestais com as espécies dos gêneros Pinus e Eucalyptus. Neste trabalho, realizaram-se estudos sobre a influência das mudanças climáticas na delimitação das zonas para plantios florestais das duas principais espécies comerciais cultivadas no Brasil pertencentes ao gênero Pinus. Foram elaborados cenários futuros, usando um programa de simulação de séries temporais, verificando as possíveis mudanças do clima e o que pode ocorrer com as mudanças de zonas de plantio das espécies florestais. Os resultados mostram que há uma tendência de diminuição da área favorável aos plantios comerciais de P. taeda e de P. elliottii no Estado do Paraná, reduzindo dos atuais 7,4 milhões de hectares favoráveis para menos de 10 mil hectares até 2080 (P. taeda), e de 10,6 milhões de hectares para menos de 4,5 mil hectares até 2080 ( $P$. elliottii), por serem espécies com alta produtividade em ambiente de clima frio e com o aumento de temperatura projetado para o futuro devem perder área para o eucalipto, entre outras, que tem espécies com maior produtividade em ambientes de maior temperatura.
\end{abstract}

Palavras-chave: mudanças climáticas globais; zonas de ocorrência; plantios florestais; zoneamento climático.

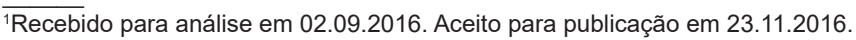

${ }^{2}$ Embrapa Florestas, Estrada da Ribeira, km 111, 83.411-000, Colombo, PR, Brasil.

3IAPAR, Rodovia Celso Garcia Cid, km 375, 86047-902, Londrina, PR, Brasil.

${ }^{4}$ Acadêmicos do Curso de Engenharia Florestal da Universidade Federal do Paraná - UFPR.

${ }^{5}$ Autor para correspondência: Marcos Silveira Wrege - marcos.wrege@embrapa.br 
ABSTRACT - Brazil is a world leader in the forestry sector, with high productivity and low costs, concentrating the forest plantations with species of the genera Pinus and Eucalyptus. In this paper, we studied the influence of global climatic changes on the delimitation of the zones for forest plantations of the two main commercial species cultivated in Brazil belonging to the genus Pinus. Future scenarios of climatic changes have been elaborated, using a time series simulation program, verifying the possible changes in the climate and what can happen with the changes in the areas of the forest species. The results show that there is a tendency to decrease the favorable area for commercial plantations of P. taeda and P. elliottii in the state of Paraná, reducing from the current 7.4 million hectares favorable to less than 10 thousand hectares, until 2080 (P. taeda), and from 10.6 million hectares to less than 4,500 hectares, until 2080 (P. elliottii), because they are species with high productivity in a cold climate environment and and with the projected rise of temperature for the future they must lose area for eucalyptus, which has species with higher productivity in higher temperature environments.

Keywords: global climate change; species occurrence; reforestation; climatic zoning.

\section{INTRODUÇÃO}

O Brasil é um dos países com maior área de plantios florestais no mundo, ocupando posição de destaque entre os maiore produtores de florestas plantadas, com a produção de pinus e eucalipto, destacando-se no ranking dos países com maior produtividade e competitividade internacional, principalmente no setor de papel celulose. O Paraná está entre os estados com maior área plantada, ocupando posição privilegiada no cenário brasileiro, sendo que as principais espécie plantadas pertencem aos gêneros Pinus e Eucalyptus (Associação Brasileira de Produtores de Florestas Plantadas - ABRAF, 2012).

Neste trabalho, são apresentadas a zonas indicadas com os menores risco climáticos para plantio de Pinus taeda e Pinus elliottii no Estado do Paraná e as possívei alterações nas delimitações das zonas favoráveis ao plantio comercial dessas espécies, considerando as mudanças climáticas globais.

No período 2005-2011, houve aumento da área plantada de florestas no Brasil de 27,9\%, o que representa crescimento de $3 \%$ a. a., sendo representada por pinus $(25,2 \%)$ e eucaliptos $(74,8 \%)$
O Paraná é o terceiro maior produtor, com 13,0\% da área plantada no Brasil, atrás de Minas Gerais $(22,7 \%)$ e São Paulo (18,2\%). Em 2012, a área plantada com florestas no Brasil foi de 6.516.000 hectares, tendo-se estagnado nos últimos dois anos por vários fatores, entre os quais a crise internacional. A área plantada com pinus e eucalipto foi de 1.477.195 ha em Minas Gerais, 1.188.403 ha em São Paulo e 846.860 ha no Paraná (ABRAF, 2012).

O Brasil passou de $5^{\circ}$ maior produtor mundial de celulose, em 2005, para o $3^{\circ}$ maio em 2011, atrás de Estados Unidos e Canadá, correspondendo a $21 \%$ do mercado internaciona de celulose, contra 9,6\% em 2005. Na produção de painéis de compensado, o Brasil ficou na $8^{\mathrm{a}}$ posição em 2011, respondendo por $6,2 \%$ do volume total transacionado internacionalmente Em 2011, o Brasil caiu da $9^{a}$ posição para a $11^{\mathrm{a}}$ na produção mundial de madeira serrada, perdendo posição para outros países da América do Sul, da Ásia e do Leste Europeu, detendo $1,2 \%$ da produção mundial, contra $2,0 \%$ anteriormente. No ranking internacional de custo de produção de celulose, o Brasil ocupa a $3^{\text {a }}$ posição, atrás do Uruguai e do Vietnam (ABRAF, 2012).
No Estado do Paraná, as principais espécies usadas em plantios florestais são as dos gêneros Pimus e Eucalyptus, espécies com exiências muito distintas, em razão de o estado se situr em uma zona de

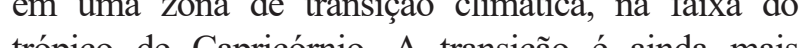
inter intensificada devido à combinação de latitudes médias com o relevo, com a predominância de altitudes menores na região norte do Estado, favorecendo a ocorrência de temperaturas mais elevadas, e com altitudes maiores na região sul, onde as temperaturas são menores. Essa diferença também pode ser retratada nos diversos tipos de vegetação, cujas espécies têm exigências climáticas distintas, pelo fato de existir no estado o clima subtropical úmido ao sul do trópico de Capricórnio (de modo geral, nas altitudes superiores a 600 metros) e tropica ao norte do paralelo (onde também prevalecem altitudes inferiores a 600 metros). As espécies altitudes inferios a 600 metros). As espécies usadas para pla a delimitadas em fuçáa das diferenças de clima utilizando-se as especies tipicas de clima tropica (geralmente situadas no norte do estado, no Vale do Ribeira e no Litoral) e as de clim temperado (situadas no sul do estado).

As geadas têm forte relação com a temperatura mínima do ar, que tem sofrido elevação nos últimos anos, quando são analisadas as séries temporais de dados climáticos dos últimos 30 anos. Em Londrina, norte do Parana a temperatura mínima aumentou $1.5{ }^{\circ} \mathrm{C}$, por exemplo, reduzindo, assim, os riscos de gead nos últimos anos (Ricce et al, 2008), embora ño os eliming riscos de geada e do fino poden dišo dos a riscos de geas e do fino podem diminuir área disponivel para uso en plantios florestais de especies de clima temperado, como as do gênero Pinus, permitindo o deslocamento mais para o sul das zonas para plantio de espécie de clima tropical.

Pinus, originado na região Sudeste dos Estados Unidos, na zona de clima temperado, é um gênero com mais de 100 espécies, que se desenvolvem nos mais diversos ambientes, desde zonas de clima temperado a tropical, nas florestas boreais, subalpinas, em florestas de clima temperado, na Costa do Mediterineo, em locais áridos e, ainda, emos mo en locais átice en anda, en montanhas Runde1, 1998). Rundel, 1998)
No Brasil, espécies do gênero Pinus são plantadas há mais de um século. Foi introduzido, inicialmente, para fins ornamentais A partir de 1960 comecou a ser explo Sul e Sulerte do Brasi. A patir da decegió de 1970, fol a principat fonte de matr da decada de 1970, foi a principal fonte de matéria-prima para o desenvolvimento da indústria florestal, abastecendo um mercado bastante diversificado. A madeir de pinus atende aos mercados de produção de laminados, de chapas, de resina, de pape e celulose. A produção de pinus foi fundamental para a substituição do uso da madeira de araucária, reduzindo a pressão pelo desmatamento desta espécie florestal nativa, favorecendo preservaç̃o da Floresta Ombrófila Mista, onde preservação da Floresta Onbrofla Mista, ond a araçr se deseno florestas plantadas para produção de papel e celulose são de pinus, produzindo material diferenciado, com qualidade superior, em relação a outras espécies (Aguiar et al., 2014). A área com plantios florestais no Paraná é de 846.860 hectares, correspondendo a 658.707 hectares plantados com pinus e 188.153 hectares com eucalipto (ABRAF, 2012).

Duas espécies de pinus têm potencial para plantio no Paraná nas regiões mais frias, sendo as mais plantadas Pinus taeda e Pinus elliottii, a diminuição dos riscos de geadas e do frio podem reduzir a área. Existem outra espécies de pinus, principalmente os tropicais, mas que ainda são pouco plantadas (Wrege et al., 2014). $P$. taeda é indicado para plantio en zonas de clima subtropical úmido, também denominado mesotérmico, de acordo com a classificaço climática de Koeppen. Desse modo, tolera as geadas, mas a temperatura mínima no ar deve ser superior a $1{ }^{\circ} \mathrm{C}$ (Higa et al., 2008). Tem maio produtividade e desenvolvimento na região $\mathrm{Su}$ do Brasil, com incrementos médios anuais (IMA) de até $40 \mathrm{~m}^{3} \cdot$ ha $^{-1} \cdot$ ano $^{-1}$ quando atinge os 18 anos, um dos maiores índices de produtividade, contra $10 \mathrm{~m}^{3} \cdot \mathrm{ha}^{-1} \cdot$ ano $^{-1}$ nos Estados Unidos, por exemplo (Higa, 2006). O verão quente, com temperaturas maiores, e os solos de textura arenos e de boa drenagem, favorecem o rendimento elevado de $P$. taeda na região Sul do Brasil. Além das condições ambientais extremamente favoráveis, o melhoramento genético colaborou para obtenção dos maiores índices de produtividade (Ferreira et al., 2005). 
P. taeda, além da região Sul do Brasil, também se desenvolve bem em Misiones Corrientes, Argentina, onde encontra condições ambientais muito favoráveis ao seu crescimento, com os maiores índices de produtividade, cquivatentes aos do Brail. É a especie de pires equivalentes aos do Brasil. É a espécie de pinus com os maiores incrementos, de acordo com relatos de empresas do setor forestal presentes no Sul do país (Ferreira et al., 2005).

As variáveis climáticas que têm maior influência sobre o pinus são a temperatura do ar e a precipitação pluviométrica, colaborando na definição dos limites de zonas favoraveis para plantios comerciais e nos índices de produtividade. A temperatura, principalmente a temperatura mínima do ar, pode definir os locais favoráveis para plantio, estando relacionada à ocorrência de geadas. A disponibilidade de água também é impoada princip prouce co pouca incererencia sobre as zonas favoráveis para os plantos connciais. Não existe, basicanente, limitação de plantio no Paraná em razão ocorrência de periodo

No Sul dos Estados Unidos, é a espéci florestal mais importante, ocupando mais de 11 milhões de hectares entre florestas nativas manejadas ou plantios comerciais. Ocorre en 14 estados do Sul dos Estados Unidos (Baker e Langdon, 1990) nas zonas de clima subtropical úmido, onde a umidade relativa elevada e os totais pluviométricos são de 1.020 a $1.500 \mathrm{~mm}$ por ano Nessas regiões, o verão quente e o inverno é ameno, com ter vera

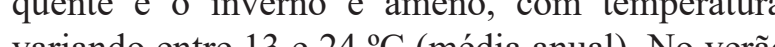
vas médi de temperaturas por chege $27{ }^{\circ} \mathrm{C}$, e as medias de temp $16^{\circ} \mathrm{C}$. As the no inverno, entre $4 \mathrm{e} 16^{\circ} \mathrm{C}$. As temperaturas extrema são de $38{ }^{\circ}$ (temperatura máxima absoluta) $-23^{\circ} \mathrm{C}$ (temperatura minima absoluta). No Estado do Paraná, a média de temperatura mínima absolut no mês mais frio do ano (julho) é de até $-6{ }^{\circ} \mathrm{C}$ e média de temperatura máxima absoluta no mês mais quente (dezembro) é de até $38{ }^{\circ} \mathrm{C}$ (Wrege et al., 2011). O período em que ocorrem geadas, em um ano, varia de 2 a 7 meses (Higa et al., 2008). Na região Sul do Brasil, as condicōes climáticas são similares às região de origem de $P$. taeda $P$. elliottii prevalecendo temperaturas um pouco ention prevalecendo tem

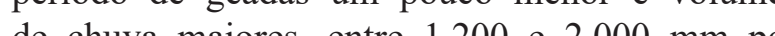
de chu maiores, e11). ano (Wrege et al., 2011).
Os estudos de cenários climáticos futuros para o Paraná, elaborados conforme o $4^{\circ}$ relatório Painel Intergovernamental de Mudanças Climéticas (AR4/IPCC) (Intergovelo de Panel on Climate Change - IPCC, 2012), são fundamentais para cécies as poss a espécies desse gênero diante das perspectivas futuras visando auxiliar políticas públicas e as empresas do setor florestal que trabalham com pinus no Paraná, considerando-se que ainda é o gênero que detém uma das especies mais amplamente utilizadas em plantios florestais no estado. $P$. taeda deve ser uma das espécies que sofrerão redução de área favorável, causada pelas alterações do clima, por ser uma espécie de clima temperado, com previsões de exuo na frontera de exploca co nul do Brasi, começando pelo Estado do Paraná, situado na zona de transição climática, junto ao Trópico de Capricórnio Assim, o objetivo deste trabalho foi identificar quais são as regiões no Estado do Paraná onde P. taeda e P. elliottii podem ser plantadas e melhor se adaptar às condições ambientais locais, nas regiões com os menores riscos climáticos e verificar as alterações nas zonas de plantio com baixos riscos, diante dos cenários de mudanças climáticas globais.

\section{MATERIAL E MÉTODOS}

Neste trabalho, foram usados dados climáticos de séries temporais da rede de estações meteorológicas do Instituto Agronômico do Paran - IAPAR e do Sistema Meteorológico do Paraná - SIMEPAR, empregando-se a série histórica com nício em 1981 e término em 2010, a qual foi

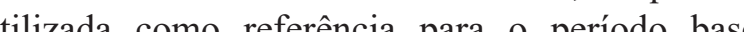

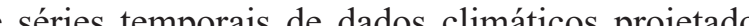

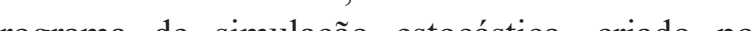
Virgens Filho et al. (2011). Forastica, criado por (e de temperaturas mínimas do ar, médias de temperatura máximas do ar, temperaturas médias do ar, médias do total acumulado em um ano de precipitação pluviométrica, para o período base, de 1981 a 2010 e para os cenários futuros, representados pelas décadas de 2011-2020; 2021-2030; 2031-2040, 2041-2050; 2051-2060, 2061-2070; 2071-2080; 2081-2090 205-2060, 2061-2070; $2071-2080 ;$ usando sistemas de informações geográficas - SIG.
A cartografia utilizada, como o modelo de superfície do terreno (United State Geological Survey - USGS, 1999) (Figura 1) e os modelos de latitude e de longitude, estavam na escala 1:250.000, o que equivale a um espaçamento de 30 metros entre cada valor, na linha do Equador. Os mapas de temperatura atual futura foram elaborados utilizando-se regressão linear múltipla, correlacionando as variávei climáticas com o modelo de superfície do terren (altitude, em metros sobre o nível do mar) (Figura 1), a latitude e a longitude (em graus decimais) Para este fim, utilizou-se a seguinte fórmula:

temperatura $=\mathrm{a}+\mathrm{b} \times$ altitude $+\mathrm{c} \times$ latitude + $\mathrm{d} \mathrm{x}$ longitude

Em que:

: constante

: coeficiente da altitude; c: coeficiente da latitude;

d: coeficiente da longitude.

\section{RESULTADOS E DISCUSSÃO}

Nos mapas dos cenários climáticos futuros, previu-se a reducão e o recuo nas zonas de plantio de pinus ( $P$. taeda e $P$. elliottii), de acordo com os relatórios do IPCC (2012) (Tabelas 1 a 5 e Figuras 2 a 5), podendo chegar a quase $100 \%$ de redução $(P$. taeda, pior cenário) ou pouco mais de 90\% ( $P$. taeda, melhor cenário), ou ainda quase $60 \%$ ( $P$. elliottii, pior cenário) ou pouco mais de $17 \%$ ( $P$. elliottii, melhor cenário) até a década de 2080, havendo, ainda, deslocamento da zona atual em direcão ao sul do estado, em zonas de maior latitude e altitude.

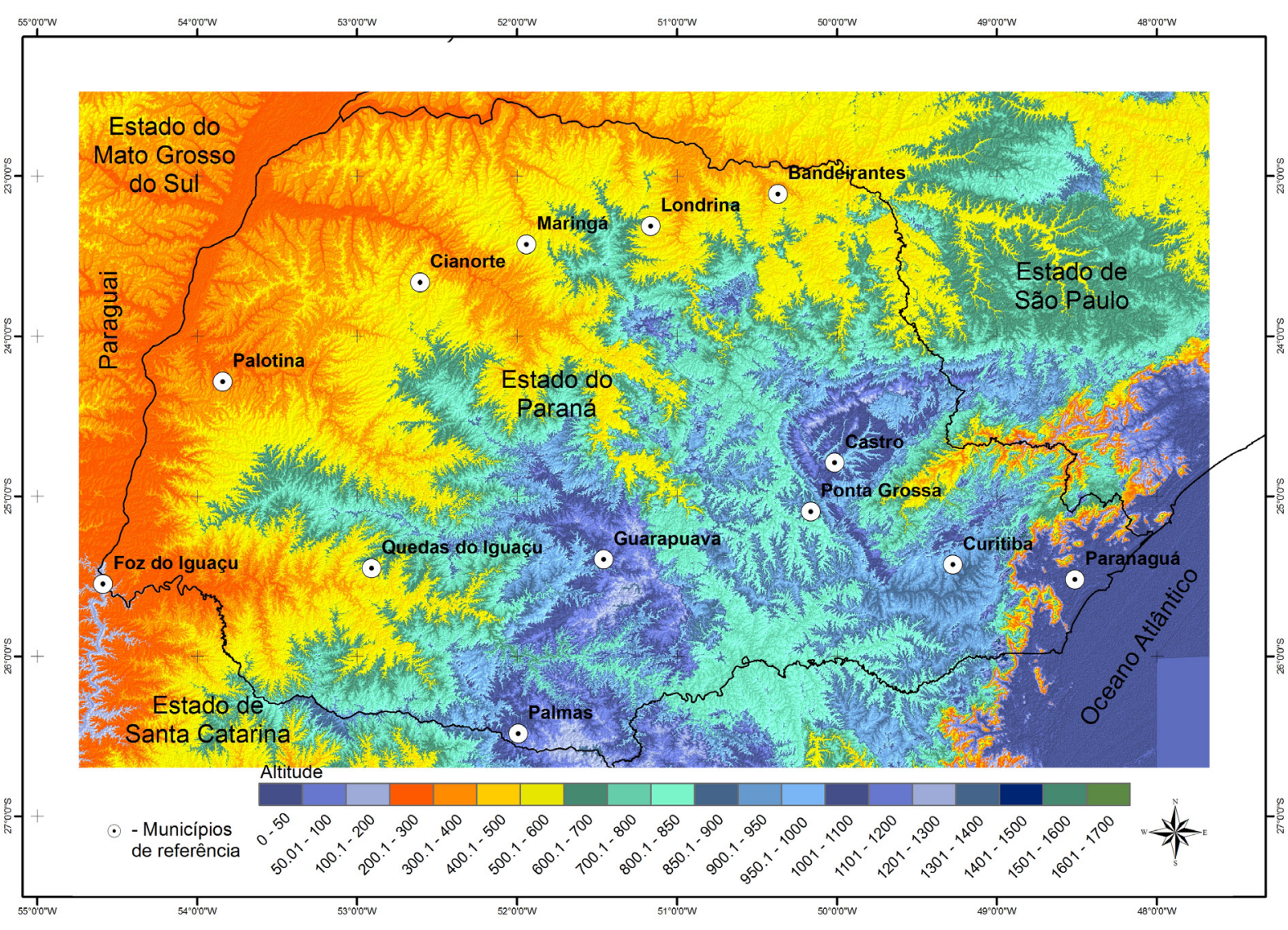

Figura 1. Modelo Numérico do Terreno - MNT do Paraná usado para interpolação dos dados de temperatura. Elaborado pelo autor a partir de dados disponíveis de Weber et al. (2004) e USGS (1999).

Figure 1. Digital Elevation Model - MNT of the state of Paraná used for interpolation of temperature. Elaborated by the author based on data available from Weber et al. (2004) and USGS (1999). 
Os mapas (Figuras 2 a 5 ) foram elaborados com duas classes: favorável ao plantio comercial e desfavorável. A cor verde representa as áreas favoráveis ao plantio e, a branca, as desfavoráveis, devido às restrições climáticas. Os limites dessas zonas foram definidos, basicamente, pela temperatura, sendo a zona classificada como favorável (de cor verde) de clima subtropical úmido e a desfavorável (de cor branca), tropical. Inclusive o Litoral, que também se encontra na cor branca, é desfavorável para pinus devido ao excesso de chuvas, que o caracteriza como tipicamente tropical. No Litoral, as chuvas são orográficas e ocorrem com maior frequência que em outras zonas devido aos contrafortes da Serra do Mar, que bloqueiam a entrada de ventos carregados de umidade vindos do oceano en direção ao continente e colaboram para que as precipitações pluviais ocorram nas encostas da Serra do Mar. Por essa razão, em virtude do grande volume de chuvas e de sua distribuição abundante em quase todos os meses, o plantio comercial de pinus não é favorável no Litoral.

As áreas não recomendadas para plantio de $P$. taeda são as áreas de transição, onde embora não existam restrições do ponto de vista climático, o incremento volumétrico é inferior aos dos pinus tropicais e inferior às regiões

preferenciais e recomendadas. Essa diferença é observada principalmente nos limites naturais do Segundo Planalto Paranaense, limitado a leste pela Escarpa Devoniana e a oeste pela Escarpa da Esperança, região com grandes área de reflorestamento. As áreas fora dos limites da classificação não são recomendadas para plantio (Higa et al., 2008)

Nas tabelas 1 a 3 são apresentadas as equações e os valores que foram elaborados par uso nos mapeamentos do período base e do cenários climáticos futuros. Os coeficientes podem ser usados nas equações de regressões da variáveis climáticas obtidas em função da latitude da longitude e da altitude de cada local, para obter os mapas do estado.

O recuo da zona favorável ao plantio, de clima frio, em relação à zona desfavorável, de clima quente, ocorre devido ao aumento da temperatura do ar, principalmente a temperatura mínima. P. taeda é uma espécie de clima temperado, com maior rendimento nas regiões de clima subtropical úmido. Assim, ocorre um recuo na fronteira de exploração em relação à região sul, em como deve ocorrer também para outra culturas de clima temperado cultivadas no Brasi (Tabela 5).

Tabela 1. Coeficientes da equação de regressão das médias das temperaturas média, máxima e mínima do ar (C) no Estado do Paraná (constante, coeficientes das latitudes, das longitudes e das altitudes) para o período base (1981-2010). Table 1. Coefficients of the regression equation for mean, maximum and minimum air temperatures $\left({ }^{\circ} \mathrm{C}\right)$ in the state of Paraná (constant, coefficients of latitudes, longitudes and altitudes) for the base period (1981-2010).

\begin{tabular}{lccc}
\hline Coeficientes & Temperatura Média & Temperatura Máxima & Temperatura Mínima \\
\hline constante & 18,7254 & 26,5170 & 20,8696 \\
latitude & 0,6836 & 0,8212 & 0,57180 \\
longitude & $-0,4024$ & $-0,4384$ & $-0,2275$ \\
altitude & $-0,0045$ & $-0,0043$ & $-0,0053$ \\
$\mathrm{r}^{2}$ & 0,82 & 0,89 & 0,82 \\
\hline
\end{tabular}

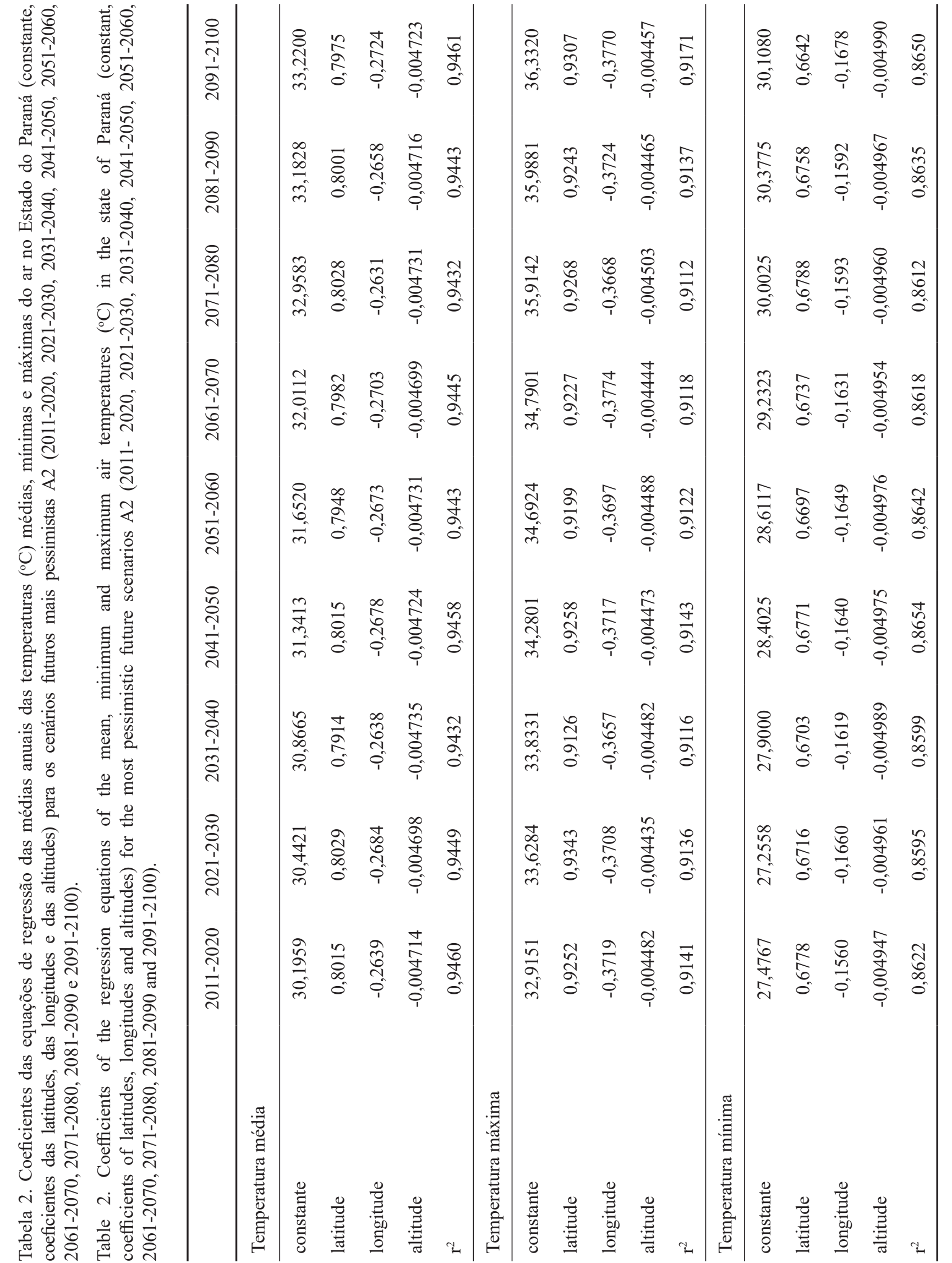

Re. 


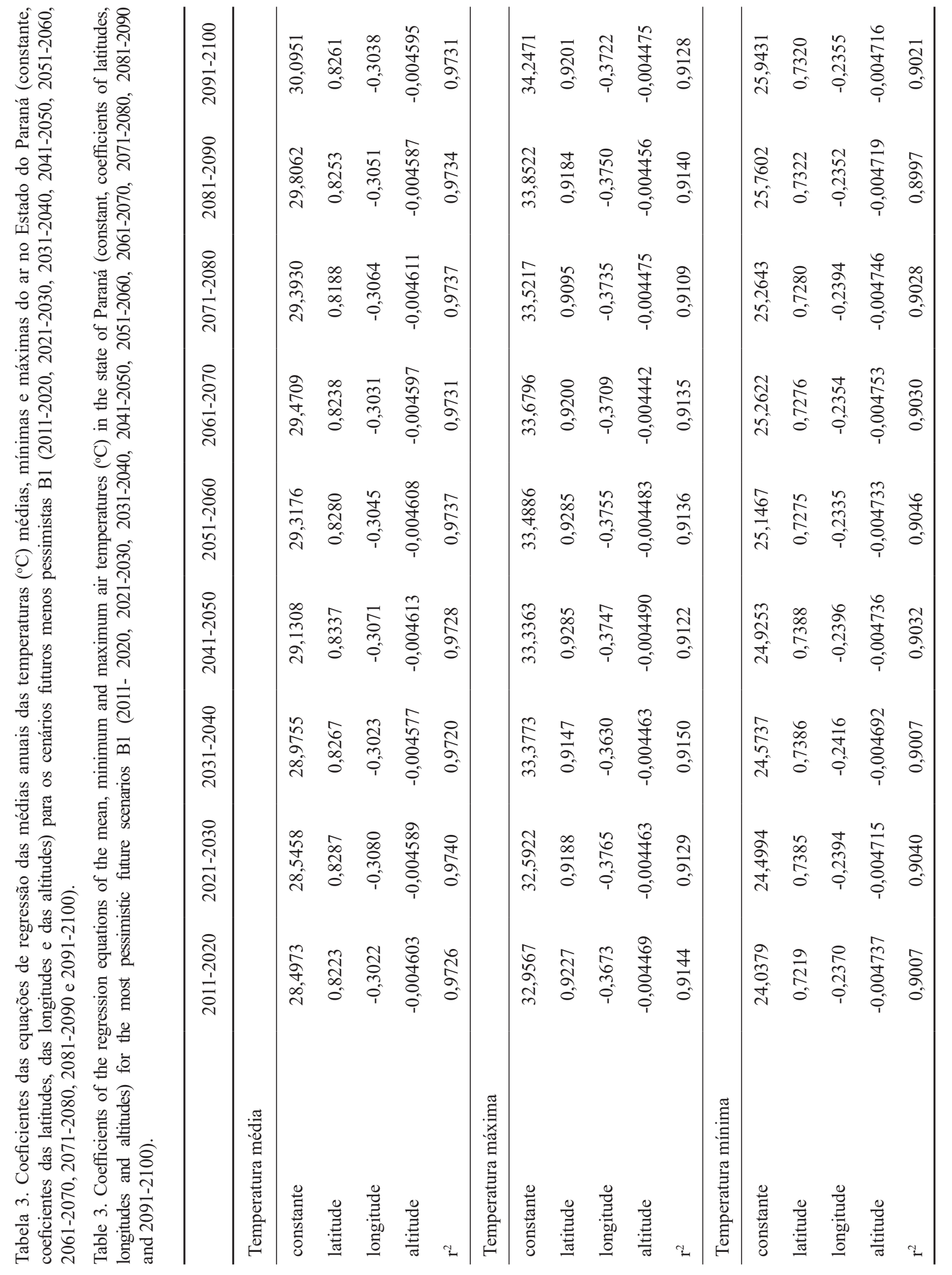

Rev. Inst. Flor. v. 28 n. 2 p. $159-175$ dez 2016
Tabela 4. Rede de estações meteorológicas do IAPAR com médias de precipitação pluviométrica acumulada por ano $(\mathrm{mm})$ projetadas para cenários climáticos futuros (décadas de 2030, 2050, 2070 e 2090).

Table 4. IAPAR weather stations network with averages of accumulated rainfall per year $(\mathrm{mm})$ projected for future climatic scenarios (decades 2030,2050, 2070 and 2090).

\begin{tabular}{lccccccc}
\hline Município & Latitude & Longitude & Altitude & 2030 & 2050 & 2070 & 2090 \\
\hline Apucarana & $-23,50$ & $-51,53$ & 746 & 1919,17 & 2059,70 & 2203,36 & 2277,93 \\
Bandeirantes & $-23,10$ & $-50,35$ & 440 & 1564,95 & 1751,52 & 1865,39 & 2044,68 \\
B. V. do Pará́so & $-22,95$ & $-51,20$ & 600 & 1661,52 & 1755,24 & 1935,93 & 2177,63 \\
Cambará & $-23,00$ & $-50,03$ & 450 & 1598,13 & 1722,40 & 1867,68 & 1975,29 \\
Cascavel & $-24,88$ & $-53,55$ & 760 & 2258,03 & 2406,67 & 2573,62 & 2839,06 \\
Cerro Azul & $-24,82$ & $-49,25$ & 360 & 1548,97 & 1699,75 & 1867,29 & 1975,09 \\
Cianorte & $-23,67$ & $-52,58$ & 530 & 1817,97 & 1999,59 & 2212,92 & 2337,98 \\
Clevelândia & $-26,42$ & $-52,35$ & 930 & 2292,70 & 2546,09 & 2664,46 & 2869,39 \\
Fernandes Pinheiro & $-25,45$ & $-50,58$ & 893 & 1800,43 & 1886,98 & 2051,79 & 2267,02 \\
Francisco Beltrão & $-26,08$ & $-53,07$ & 650 & 2361,78 & 2479,34 & 2665,37 & 2893,61 \\
Guarapuava & $-25,35$ & $-51,50$ & 1058 & 2092,35 & 2280,36 & 2452,40 & 2615,09 \\
Guaraqueçaba & $-25,27$ & $-48,53$ & 40 & 2688,18 & 2869,56 & 3070,93 & 3333,73 \\
Ibiporã & $-23,27$ & $-51,02$ & 484 & 1670,88 & 1737,06 & 1921,11 & 2095,19 \\
Joaquim Távora & $-23,50$ & $-49,95$ & 512 & 1616,71 & 1733,16 & 1893,20 & 2011,31 \\
Laranjeiras do Sul & $-25,42$ & $-52,42$ & 880 & 2255,19 & 2511,66 & 2696,11 & 2853,47 \\
Londrina & $-23,37$ & $-51,17$ & 585 & 1864,56 & 2021,83 & 2097,29 & 2241,13 \\
Morretes & $-25,50$ & $-48,82$ & 59 & 2263,01 & 2388,11 & 2544,23 & 2717,34 \\
Nova Cantu & $-24,67$ & $-52,57$ & 540 & 2176,71 & 2295,35 & 2430,89 & 2727,37 \\
Palmas & $-26,48$ & $-51,98$ & 1100 & 2293,51 & 2465,82 & 2689,09 & 2941,16 \\
Palotina & $-24,30$ & $-53,92$ & 310 & 1808,54 & 2013,23 & 2203,02 & 2360,74 \\
Paranavaí & $-23,08$ & $-52,43$ & 480 & 1608,84 & 1818,29 & 1873,92 & 1983,81 \\
Pato Branco & $-26,12$ & $-52,68$ & 700 & 2284,78 & 2584,41 & 2679,49 & 2942,01 \\
Pinhais & $-25,42$ & $-49,13$ & 930 & 1619,22 & 1761,94 & 1907,40 & 2037,41 \\
Planalto & $-25,70$ & $-53,78$ & 400 & 2113,78 & 2283,97 & 2516,05 & 2661,70 \\
Ponta Grossa & $-25,22$ & $-50,15$ & 880 & 1844,25 & 2079,70 & 2153,08 & 2269,27 \\
Quedas do Iguaçu & $-25,52$ & $-53,02$ & 513 & 2328,80 & 2494,93 & 2670,28 & 2790,40 \\
Telêmaco Borba & $-24,33$ & $-50,62$ & 768 & 1788,52 & 1926,13 & 2033,21 & 2230,34 \\
Umuarama & $-23,73$ & $-53,28$ & 480 & 1814,04 & 1933,63 & 2050,98 & 2223,06 \\
\hline & & & & & & &
\end{tabular}

Rev. Inst. Flor. v. 28 n. 2 p. $159-175$ dez. 2016 
Tabela 5. Alteração de áreas de plantio comercial de pinus no Paraná de acordo com cenários de mudanças climáticas globais Table 5. Change of commercial pine plantation areas in the state of Paraná according to global climate change scenarios.

\begin{tabular}{|c|c|c|c|c|c|}
\hline \multirow{3}{*}{ Cenário } & \multirow[b]{2}{*}{ Década } & \multirow{2}{*}{$\begin{array}{c}\text { P. taeda } \\
\text { Área Favorável } \\
\text { (ha) }\end{array}$} & \multicolumn{3}{|c|}{ P. elliottii } \\
\hline & & & $\begin{array}{l}\text { Redução de Área } \\
(\%)\end{array}$ & $\begin{array}{c}\text { Área Favorável } \\
\text { (ha) }\end{array}$ & $\begin{array}{l}\text { Redução de Área } \\
(\%)\end{array}$ \\
\hline & Atual & 7.431 .269 & 0,0 & 10.664 .518 & 0,0 \\
\hline \multirow{7}{*}{ A2 } & $2011-2020$ & 3.707 .482 & 50,1 & 9.499 .330 & 10,9 \\
\hline & $2021-2030$ & 1.940 .955 & 73,9 & 9.659 .570 & 9,4 \\
\hline & 2031-2040 & 711.933 & 90,4 & 8.888 .520 & 16,6 \\
\hline & 2041-2050 & 351.280 & 95,3 & 7.942 .980 & 25,5 \\
\hline & 2051-2060 & 121.093 & 98,4 & 7.075 .323 & 33,6 \\
\hline & $2061-2070$ & 44.472 & 99,4 & 5.645 .090 & 47,0 \\
\hline & 2071-2080 & 9.844 & 99,9 & 4.509 .780 & 57,7 \\
\hline \multirow{7}{*}{ B1 } & $2011-2020$ & 4.412 .390 & 40,6 & 8.891 .083 & 16.6 \\
\hline & $2021-2030$ & 3.714 .345 & 50,0 & 9.301 .779 & 12,7 \\
\hline & 2031-2040 & 2.643 .619 & 64,4 & 9.348 .313 & 12,3 \\
\hline & $2041-2050$ & 2.123 .870 & 71,4 & 9.402 .661 & 11,8 \\
\hline & 2051-2060 & 1.558 .877 & 79,0 & 9.377 .590 & 12,0 \\
\hline & $2061-2070$ & 981.738 & 86,8 & 9.223 .618 & 13,5 \\
\hline & $2071-2080$ & 582.701 & 92,2 & 8.811 .659 & 17,3 \\
\hline
\end{tabular}

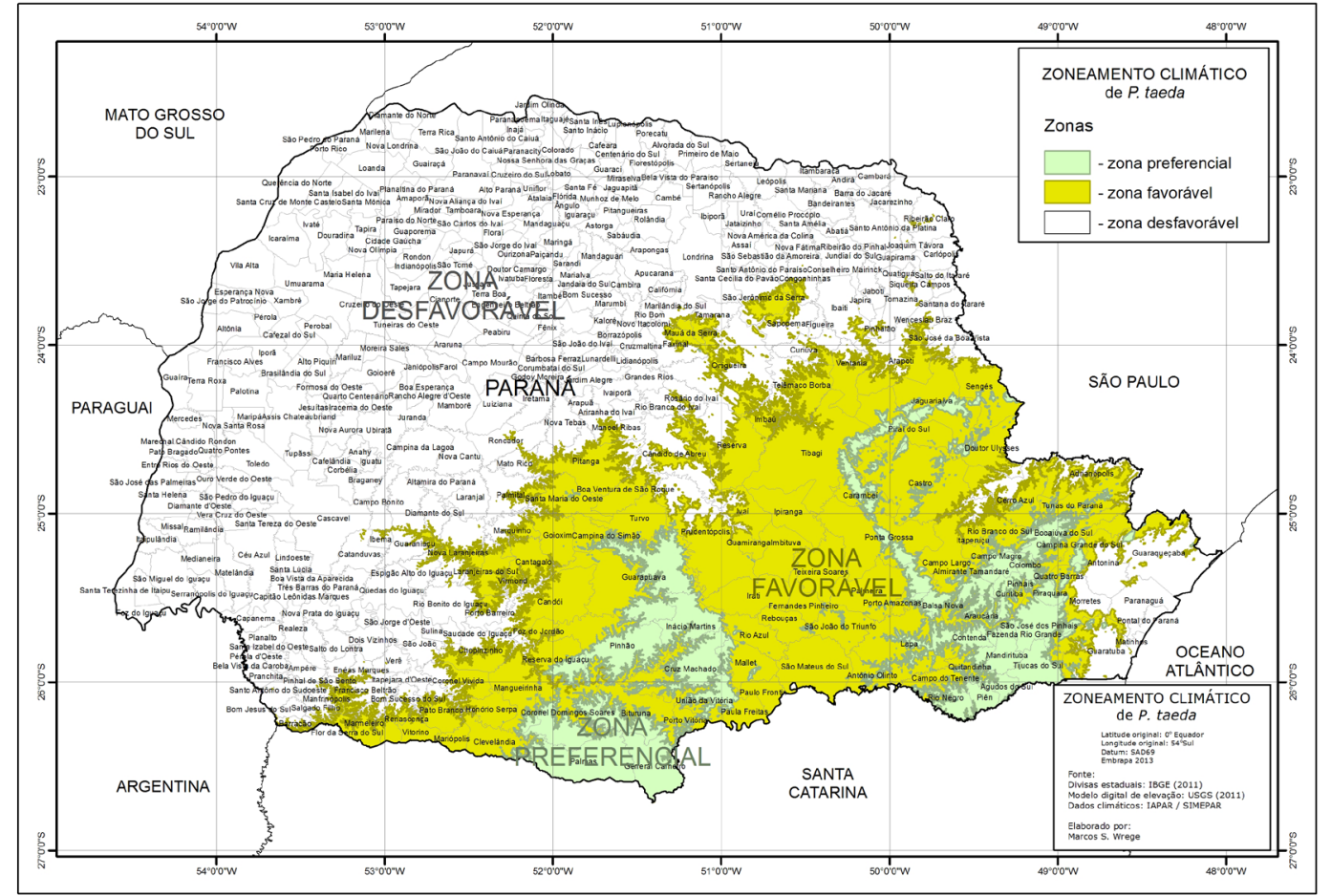

Figura 2. Regiões com potencial para plantios florestais com $P$. taeda no Estado do Paraná. Figure 2. Regions with potential for forest plantations with P. taeda in the state of Paraná.

Rev. Inst. Flor. v. 28 n. 2 p. $159-175$ dez. 2016
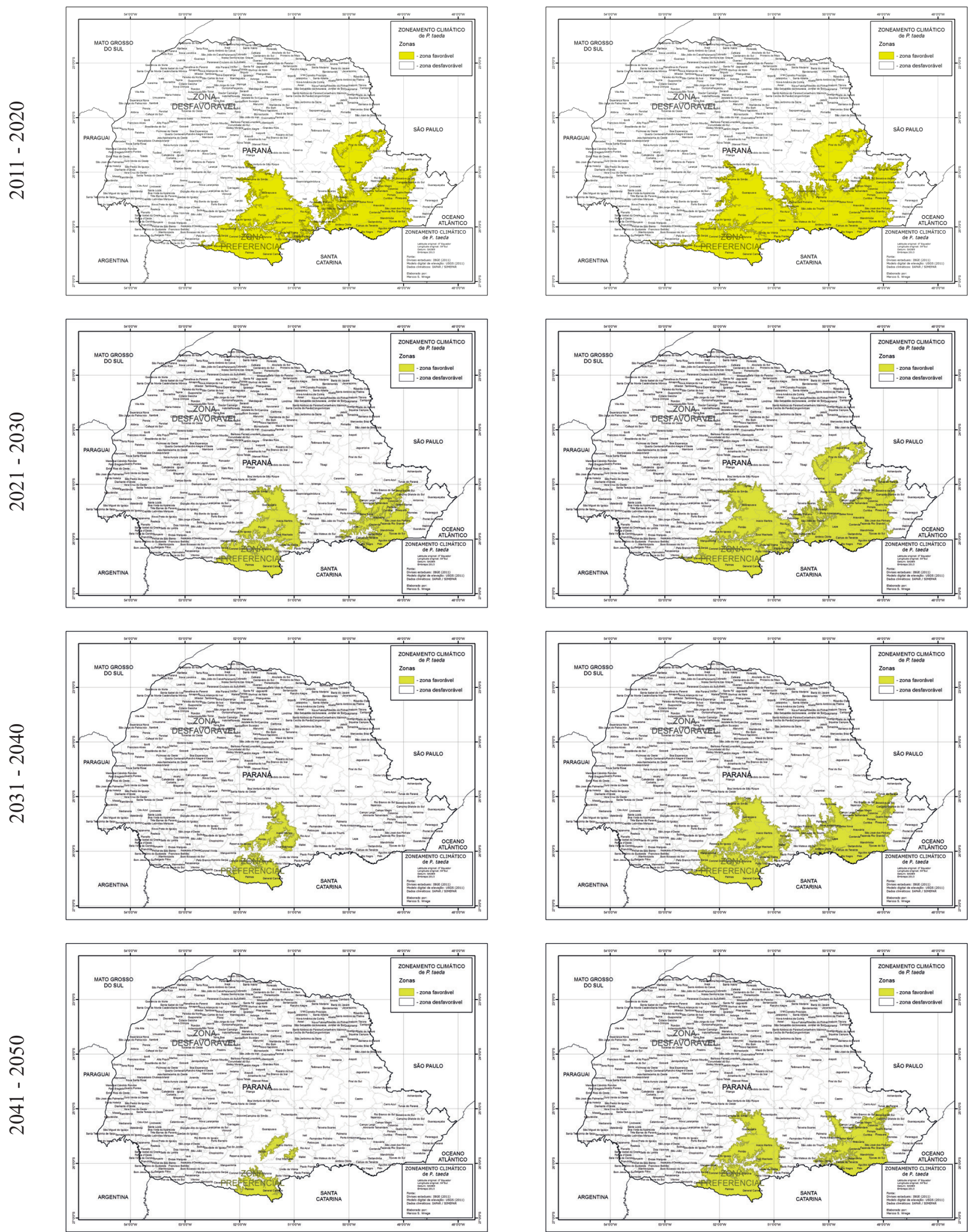

Figura 3a. Novos cenários de regiões com potencial para plantios florestais com P. taeda no Estado do Paran Figure 3a. New scenarios of regions with potential for forest plantations with $P$. taeda in the state of Paraná.

ev. Inst. Flor. v. 28 n. 2 p. $159-175$ dez. 2016 

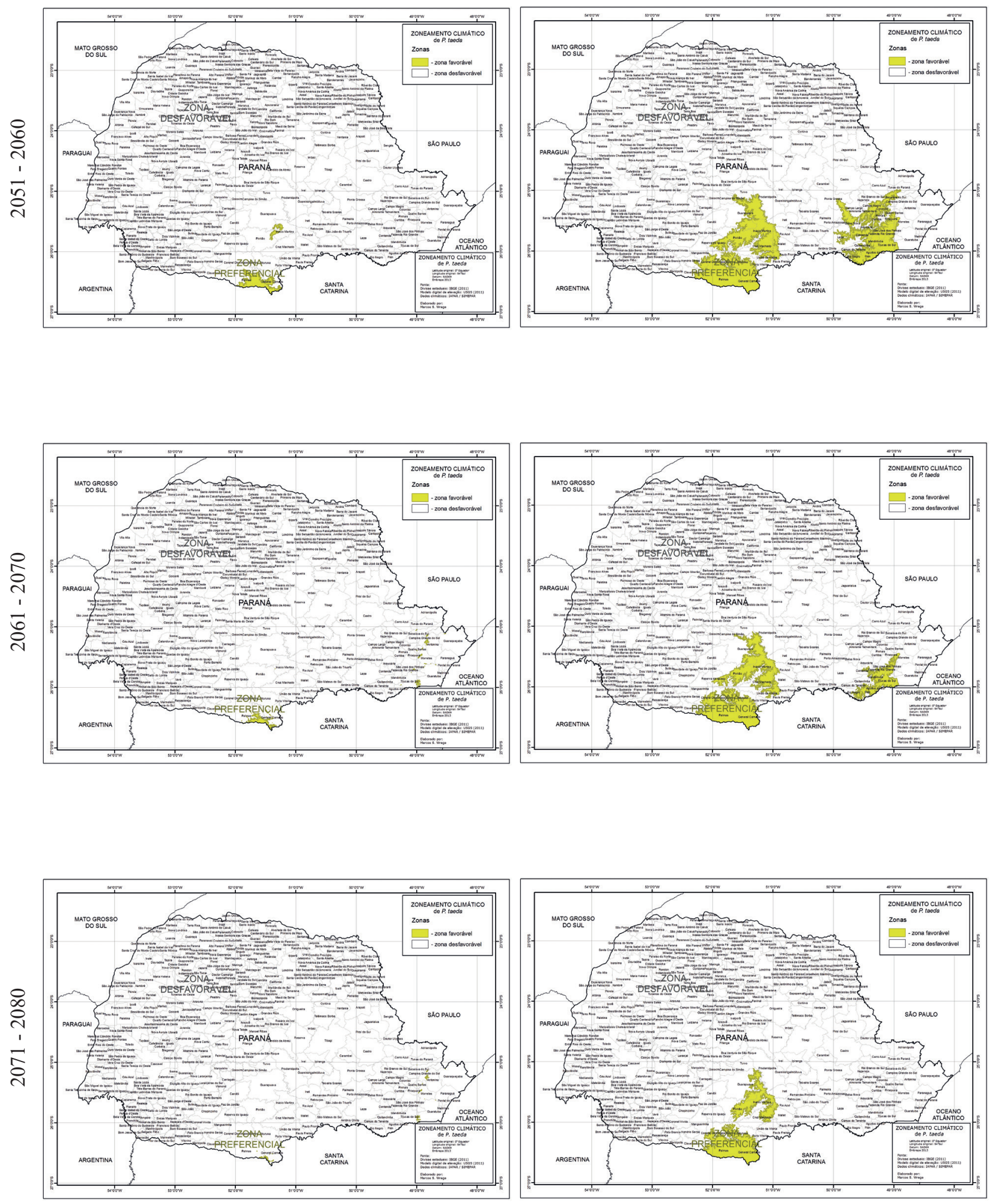

Figura 3b. Novos cenários de regiões com potencial para plantios florestais com P. taeda no Estado do Paraná Figure 3b. New scenarios of regions with potential for forest plantations with $P$. taeda in the state of Paraná.

Rev. Inst. Flor. v. 28 n. 2 p. $159-175$ dez. 2016
WREGE, M.S. et al. Plantios com pinus no Paraná e cenários de mudanças climáticas.

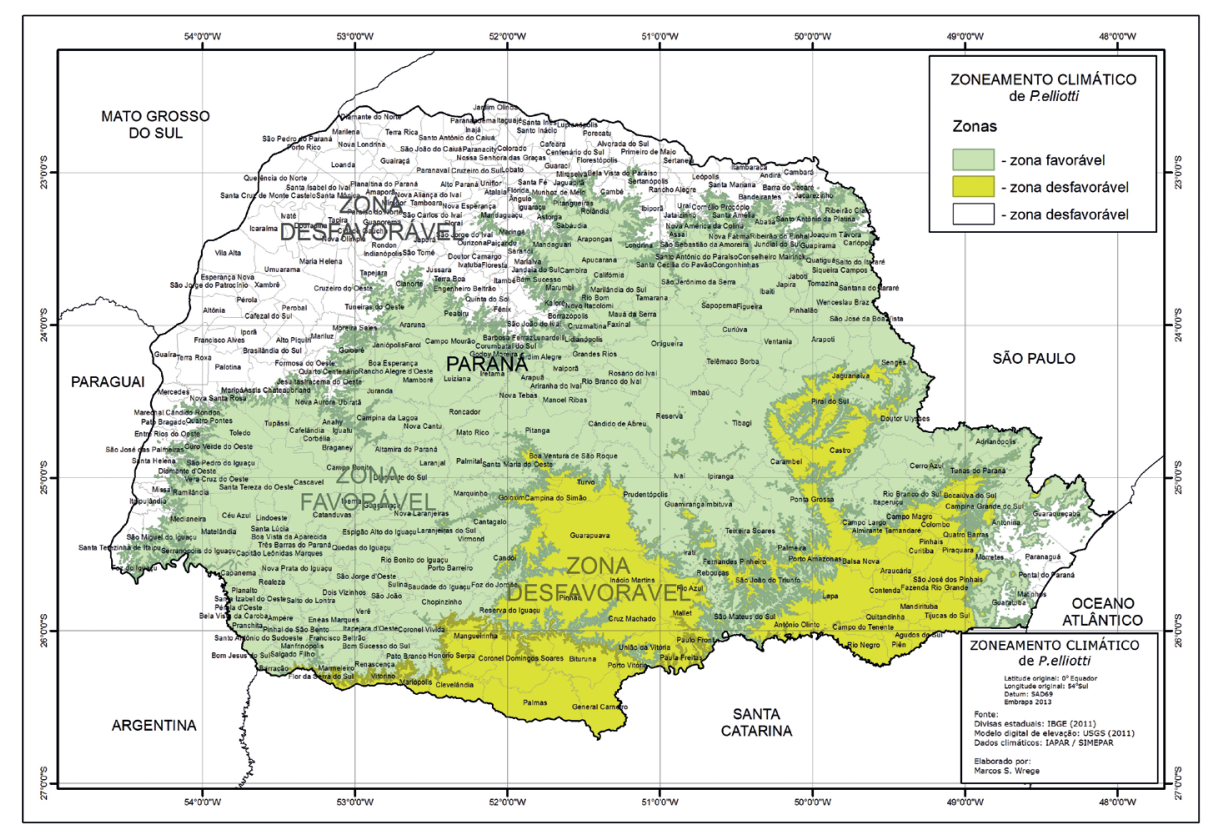

Figura 4. Regiões com potencial para plantios florestais com P. elliottii no Estado do Parana Figure 4. Regions with potential for forest plantations with P. elliottii in the state of Paraná.
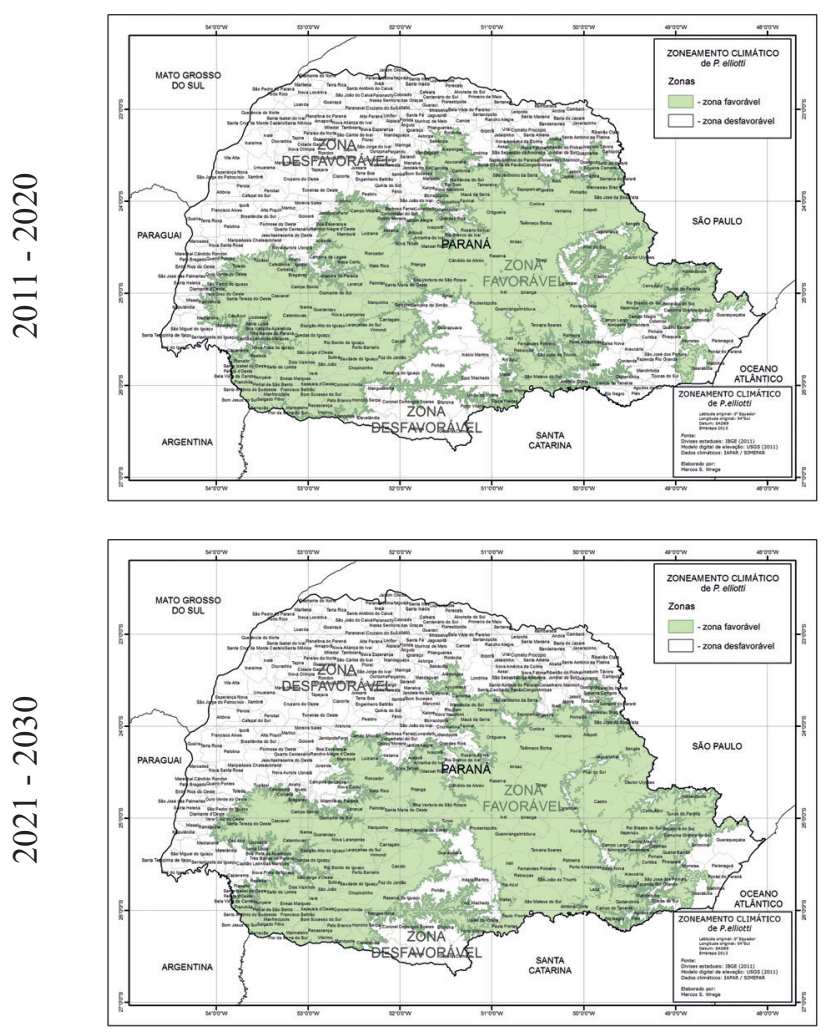
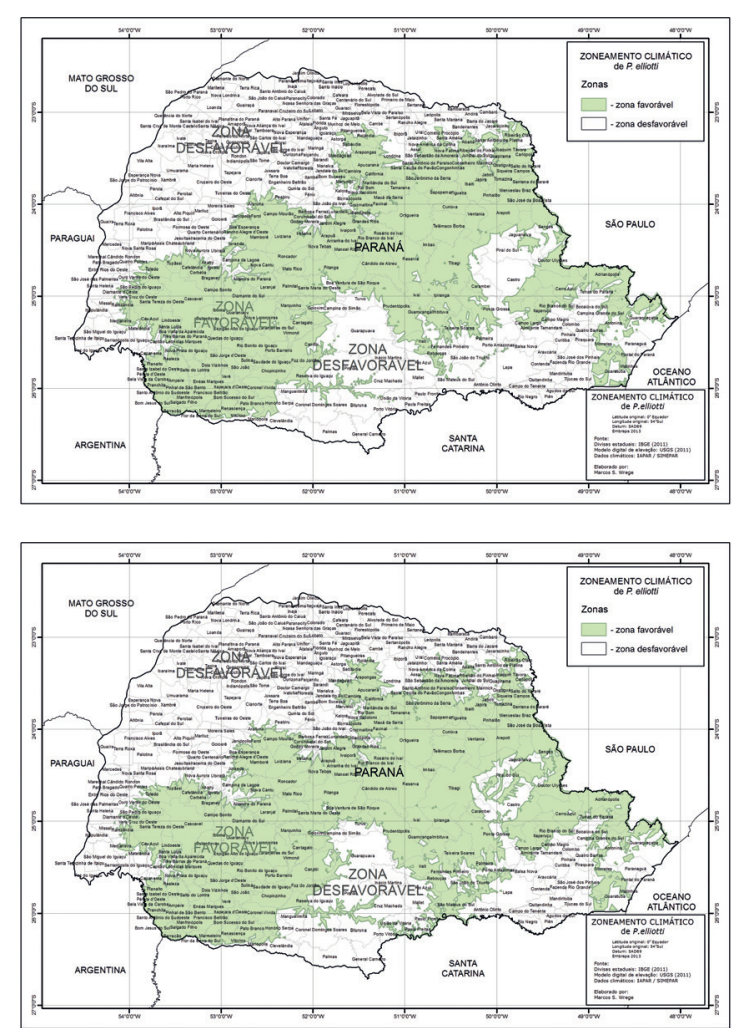

Figura 5a. Novos cenários de regiões com potencial para plantios florestais com $P$. elliottii no Estado do Paraná. Figure 5a. New scenarios of regions with potential for forest plantations with $P$. elliottii in the state of Paraná.

Rev. Inst. Flor. v. 28 n. 2 p. $159-175$ dez. 2016 

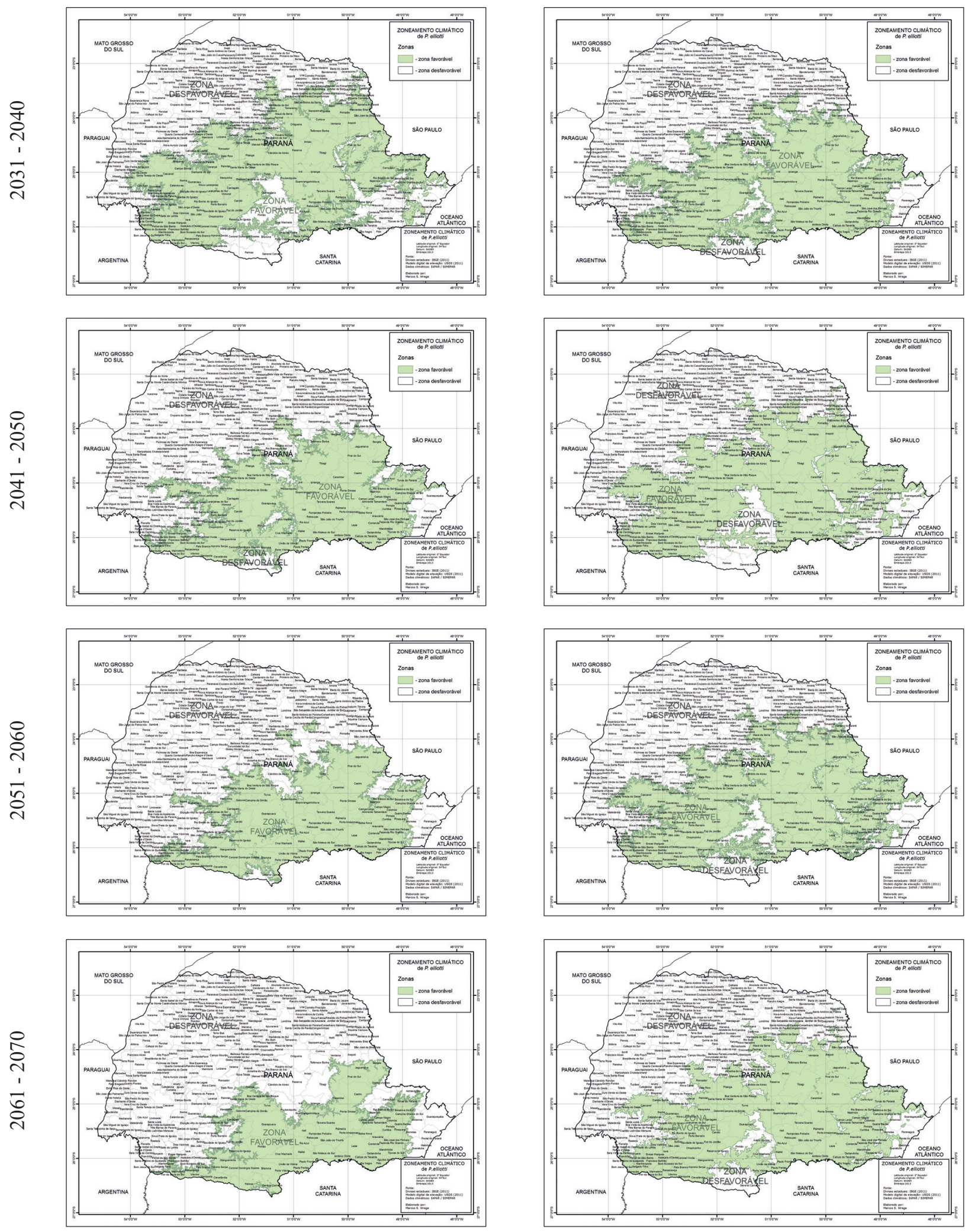

Figura 5 b. Novos cenários de regiões com potencial para plantios florestais com P. elliottii no Estado do Paraná. Figure $5 \mathrm{~b}$. New scenarios of regions with potential for forest plantations with $P$. elliottii in the state of Paraná.

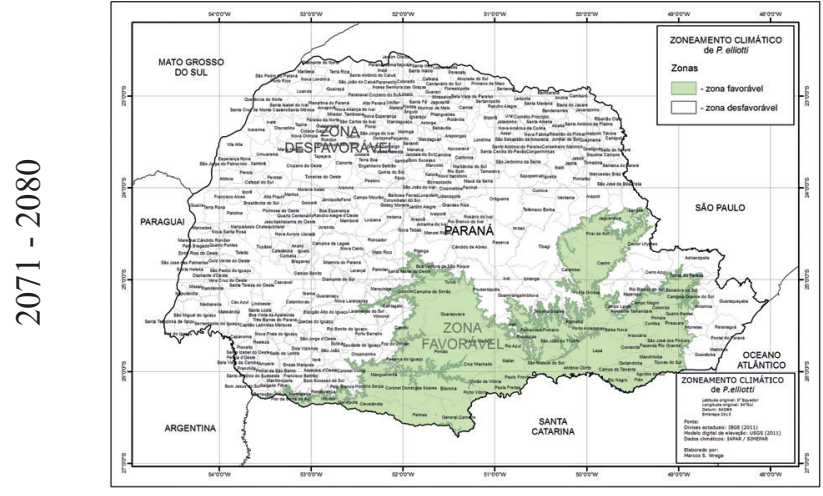

Figura 5c. Novos cenários de regiões com potencial para plantios florestais com P. elliottii no Estado do Paraná. Figure $5 \mathrm{c}$. New scenarios of regions with potential for forest plantations with P. elliottii in the state of Paraná

Nas figuras são apresentados dois cenários, A2 e B1. O que se pode verificar é que, nas próximas décadas, se a progressão das emissões pe gases de efito estufa continuar como está, er significativa redução nas zonas mais ndicadas para plantio de $P$. taeda no Estado do Paraná, tendendo a se concentrar mai ao sul, onde as temperaturas devem permanece frias, com condições favoráveis para plantio comercial até, pelo menos, a década de 2060 (cenário mais pessimista), ou até a década de 2080 (cenário menos pessimista).

Considerando-se os cenários apresentados, verifica-se a importância para o desenvolvimento de programas de melhoramento genético, principalmente para $P$. taeda, espécie mais plantada, com o desenvolvimen de materiais de maior produtividade e de boa qualidade de madeira em condições de clima mais quente, caso contrário os plantios comerciais de pinu tenderão a ser trocados pelos plantios de eucalipto de outras espécies florestais de alto rendimento em clima quente.

Embora atualmente não haja restrições em relação à disponibilidade de água para o desenvolvimento de pinus na região $\mathrm{Sul}$ devido às mudanças climáticas, é importante que sejam desenvolvidos materiais com maior tolerância à seca, porque poderão ocorrer mudanças na distribuiç̃a das chuvas, com possibilidade de projecões de aumento de chuvas na região Sul do país.

\section{CONCLUSÕES}

Com as mudanças climáticas globais, as projeções indicam aumento da temperatura do ar, principalmente das temperaturas mínimas, que ocorrem com mais frequência à noite. Assim, a tendência é de haver aumento da respiração das plantas, podendo haver redução da fotossíntese líquida de $P$. taeda e de $P$. elliottii, repercutindo na redução da produção comercial.

Ocorrerá diminuição das áreas de baixo risco para plantio comercial de $P$. taeda e $P$. elliottii, em função do aumento da temperatura do ar favorecendo o plantio de outras espécies mai bem adaptadas e com maior produtividade em clima quente. As zonas de maior altitude no Sul do país ainda permanecerão favoráveis ao plantio das duas espécies.

Programas de melhoramento genético para $P$. taeda e P. elliottii precisarão ser desenvolvidos, caso ainda haja intenção de manter essas espécies como opção para plantio comercial, focando no desenvolvimento de materiais mais bem adaptados às condições de invernos e de noites com temperatura maiores que as atuais, além de considerar também a adaptação às estiagens, mesmo com projeção de maiores volumes de chuva no futuro, devido à possibilidade de irregularidade na distribuição das chuvas ao longo do ano. 


\section{AGRADECIMENTOS}

À FINEP, pelo apoio financeiro concessão de bolsas de estudo (por meio do Conselho Nacional de Desenvolvimento Científico Tecnológico - CNPq) para os estudantes do curso de graduação em Engenharia Florestal da Universidade Federal do Paraná - UFPR. Este artigo é parte do resultado do projeto "Simulação dos Impactos das Mudanças Climáticas Globais sobre os Setores da Agropecuária, Floresta e Energia" - SIMCAFE - Met Física 7 - financiado pela Financiadora de Estudos Projetos - FINEP (convênio 01.09.0324.00), liderado pelo Instituto Agronômico do Paraná - IAPAR).

\section{REFERÊNCIAS BIBLIOGRÁFICAS}

AGUIAR, A.V.; SOUSA, V.A.; SHIMIZU, J. Espécies de pinus mais plantadas no Brasil. In:

Sistema de produção do Pinus. Colombo: Embrap Florestas, 2014. Disponível em: $<$ https://www.spo cnptia.embrapa.br>. Acesso em: 8 dez. 2016.

ASSOCIAÇÃO BRASILEIRA DE PRODUTORES DE FLORESTAS PLANTADAS - ABRAF. Anuário estatístico da ABRAF 2012: ano base 2011. Brasília, DF, 2012. 136 p. Disponível em: $<\mathrm{http}$ //www abraflor. ABRAF12-BR.pdf>. Acesso em: 3 jun. 2013.

BAKER, J.B.; LANGDON, O.G. Pinus taeda L. In: BURNS, R.M.; HONKALA, B.H. (Coord.) Silvics of North America. Washington, DC: Unites States Department of Agriculture, Forest Service, 1990. v. 1, p. 497-512. (USDA. For. Serv. Agric. Handbook, 654)

FERREIRA, F.A.; MENDES, J.E.P.; MAIA, J.L Mortalidade de estacas enraizadas de Pinus spp. causada por Rhizoctonia solani. Fitopatologia Brasileira, v. 30, n. 2, p. 201, mar./abr. 2005.

HIGA, R.C.V. Dinâmica de carbono de Pinus taeda L. voltadas a exigências climáticas práticas silviculturais. [Gainesville]: University of Florida, [2006]. 62 p. (Relatório final pós-doutorado) (Não publicado)
HIGA, R.C.V. et al. Zoneamento climático: Pinus taeda no Sul do Brasil 2008, CD-Rom. Disponível em: <http://www.infoteca.cnptia. mbrapa.br/handle/doc/315638> Acesso en 8 dez. 2016.

NTERGOVERNMENTAL PANEL ON CLIMATE CHANGE - IPCC. Summary for policymakers. In: FIELD, C.B. et al. (Ed.). Managing the isks of extreme events and disasters advance climate change adaptation: a specia report of working groups I and II of the Intergovernmental Panel on Climate Change. Cambridge: Cambridge University Press, 2012. p. 1-19.

RICCE, W.S. et al. Estudo das temperaturas minimas e máximas no estado do Paraná. In: SIMPOSIO BRASILEIRO DE CLIMATOLOGIA GEOGRAFICA, 8., 2008, Alto Caparaó. Anais.. Natal: SBCG, 2008. p. 200-210.

RICHARDSON, D.M.; RUNDEL, P.W. Ecology and biogeography of Pinus: an introduction. In: RICHARDSON, D.M. (Ed.). Ecology and biogeography of Pinus. Cambridge: Cambridge University Press, 1998. p. 3-46.

UNITED STATE GEOLOGICAL SURVEY USGS. Survey National Mapping Division: Global 30 arc second elevation data. 1999. Disponível em: <http://edcwww.cr.usgs.gov/ landdaac/gtopo30/gtopo30.html>. Acesso em: 10 jul. 1999.

VIRGENS FILHO, J.S. et al. PGECLIMA_R: gerador estocástico para simulação de cenário climáticos brasileiros: I - Desenvolvimento do gerenciador do banco de dados climáticos. In: CONGRESSO BRASILEIRO DE AGROMETEOROLOGIA, 17., 2011, Guarapari. Anais... Guarapari: Sociedade Brasileira de Agrometeorologia, 2011. v. 1. p. 1-5

WEBER, E.; HASENACK, H.; FERREIRA, C.J. Adaptação do modelo digital de elevação do SRTM para o sistema de referência oficia brasileiro e recorte por unidade da federação. Porto Alegre: Universidade Federal do Rio Grande do Sul Centro de Ecologin, 2004.

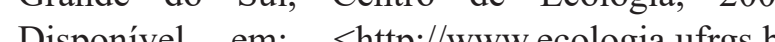
labgeo $>$. Acesso em: 17 jul. 2008.
WREGE, M.S. et al. Atlas climático da região Sul do Brasil: estados do Paraná, Santa Catarina e Rio Grande do Sul. Pelotas: Embrapa Clim Temperado; Colombo: Embrapa Florestas, 2011.

et al. Pinus tropical com potencial para so em plantios comerciais no Brasil. Revista do Instituto Florestal, v. 26, p. 137-145, 2014. 